\title{
Virtual Computing Laboratories: A Case Study with Comparisons to Physical Computing Laboratories
}

\author{
Stephen D. Burd and \\ Alessandro F. Seazzu \\ Anderson School of \\ Management, University of \\ New Mexico, Albuquerque, \\ New Mexico, USA \\ burd@mgt.unm.edu; \\ alex@mgt.unm.edu
}

\author{
Christopher Conway \\ Sam M. Walton College of \\ Business, University of \\ Arkansas, Fayetteville, \\ Arkansas, USA
}

\section{Executive Summary}

Current technology enables schools to provide remote or virtual computing labs. Virtual computing labs can be implemented in multiple ways ranging from remote access to banks of dedicated workstations to sophisticated access to large-scale servers hosting virtualized workstations. This paper reports on the implementation of a specific lab using remote access to dedicated workstations and supporting students enrolled in degree programs in management. Such a lab can be implemented at relatively low cost by reallocating resources dedicated to existing physical labs.

Our virtual computing lab was implemented as part of wider initiative to incorporate mobile computing throughout the curriculum. The lab was intended to improve student access to school computing resources and provide a reliable and standardized software and hardware environment for use in management courses.

Virtual computing labs pose significant challenges in configuration, operation, and administration. All of these challenges can be adequately addressed with sufficient planning and management. We provide direct comparisons of physical and virtual computing labs in the areas of security, administration, and cost.

We report generally positive student perceptions of the virtual computing lab as compared to the previous physical computing lab with respect to accessibility, usability, and value, though those perceptions vary depending on student background and technical skill. Non-technical students can be overwhelmed or disoriented when using a virtual computing lab. Addressing this problem

Material published as part of this publication, either on-line or in print, is copyrighted by the Informing Science Institute. Permission to make digital or paper copy of part or all of these works for personal or classroom use is granted without fee provided that the copies are not made or distributed for profit or commercial advantage AND that copies 1) bear this notice in full and 2) give the full citation on the first page. It is permissible to abstract these works so long as credit is given. To copy in all other cases or to republish or to post on a server or to redistribute to lists requires specific permission and payment of a fee. Contact Publisher@InformingScience.org to request redistribution permission. requires devoting sufficient resources to training, user interface design, and ongoing support for both student and faculty users.

Keywords: computer security, computing laboratory, network administration, system administration, virtual lab, virtual machine 


\section{Introduction}

Students use computers extensively both within and outside of the classroom to conduct research, complete assignments, and interact with instructors and other students. Many colleges and universities provide computing laboratories for student use-typically distributed across campus locations, containing dozens to hundreds of computers, and providing both general- and specialpurpose software applications. Campus computing labs provide many benefits to students including enabling them to avoid hardware and software purchase, maintenance, and administration (Hawkins \& Oblinger, 2007). Conversely, campus computing labs are a considerable expense to educational institutions, and their operation, maintenance, and administration is complex.

Among students on a typical campus, laptops have become nearly as common as cell phones and MP3 players (Caruso, 2007; Oberdick, 2006). Some schools require laptop ownership, with specified configuration requirements, by students though such a requirement is unrealistic in many public schools. Unfortunately for campus administrators, the rise of laptop and other computer ownership among students has not eliminated the need for campus computing laboratories. Reasons for the continued need include the lack of computer ownership among some student populations, lack of raw computing power in many student-owned computers, need for standardized software and hardware configurations to support some educational activities, and the cost and complexity of many specialized software applications (Hawkins $\boldsymbol{\&} \boldsymbol{R} \boldsymbol{u d y} 2006$ ).

Advances in networking, operating systems, and virtual machine technology now make it possible to implement labs that lack the physical "presence" associated with traditional campus computing labs. Such labs are sometimes called remote labs (Ma \& Nickerson, 2006), web labs (Ross, Boroni, Goosey, Grinder, \& Wissenbach, 1997), distributed learning labs (Winer, Chomienne, \& Vazquez-Abad, 2000), or virtual labs (Ko et al., 2000). We will use the term virtual lab $(\boldsymbol{V} \boldsymbol{L} \boldsymbol{A B})$ for the remainder of this paper. Like traditional physical computing labs, virtual labs have their own strengths and weaknesses, costs and benefits, capabilities, and limitations. They also present unique technical and other challenges.

This paper describes our implementation of a virtual computing lab in one college of a large public university. We describe how and why the lab was created, its operational details, and its capabilities and limitations with respect to undergraduate and graduate programs in management across a variety of concentrations and courses. We report practical considerations of technology, cost, and security, and also examine student perceptions. Our purpose is to add and provide guidance to faculty and administrators who are considering implementing a VLAB at their school.

\section{Physical and Virtual Computer Labs}

For the purposes of this paper, a physical computing laboratory (PLAB) is defined as a campus location with the following characteristics:

- Houses multiple general-purpose personal or desktop computers, hereinafter called workstations

- Provides workstation network access sufficient to support course-related activities and assignments

- Provides one or more standardized software configurations encompassing the operating system, utilities, and application software

- Ensures physical security of workstations and related equipment

- Provides space and furnishings that enable students to directly interact with workstations (e.g., desks and chairs) 
- Provides sufficient workstation I/O and storage capability to support direct user interaction (e.g., keyboard, mouse, video display, CD/DVD drive, and a USB port for portable or flash storage devices)

A VLAB has all of the above characteristics except the last two (i.e., students do not physically interact with the lab computers). There are various ways of organizing and implementing VLABs including:

- Remote access to multiple single-user computer systems

- Remote access to one or more multiuser computer systems

- Remote access to multiple virtual machines hosted within one or more physical servers

Figure 1 illustrates an interaction scenario with the first type of VLAB. A user physically interacts with a laptop computer which in turn hosts a software-based interface to access one of a group of VLAB workstations via the Internet. The software interface can be implemented via telnet, HTTP, Microsoft Remote Desktop services, and other methods. Users may be physically located in classrooms, libraries, common areas, home, and work - anywhere with sufficient network services and capacity.

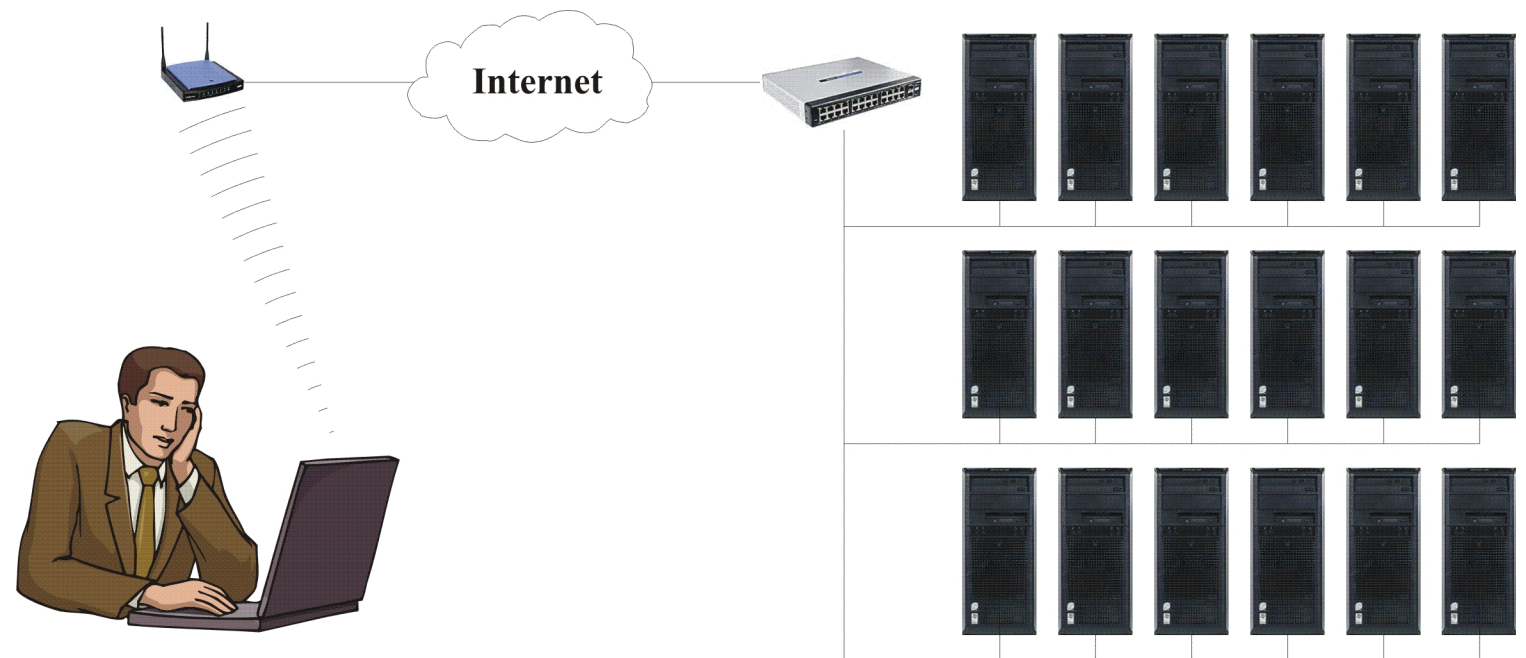

Figure 1. User interaction with a VLAB containing multiple workstations

VLABs may also employ one or more server computers that emulate single-user workstations, thus replacing the group of workstations in Figure 1 with a smaller number of rack-mounted servers. Software such as Citrix or Microsoft Terminal Services can be deployed on the servers to provide access to emulated workstations. Virtual machine software can also be deployed on rackmount servers to execute virtual workstations that are operationally similar to single-user workstations and their operating and application software. Supporting software includes VMware ESX and Microsoft Virtual Server.

For the remainder of this paper we will assume the approach to VLAB implementation depicted in Figure 1 though many of the comparisons we will make between PLABs and our particular VLAB implementation are applicable to other VLAB implementations. Our reasons for selecting this approach are described later.

VLABs have been discussed primarily in educational literature for engineering and the sciences. Much of that literature is devoted to remote operation of laboratory equipment, though some arti- 
cles discuss remote control of distant computer hardware and software (Sicker, Lookabaugh, Santos, \& Barnes, 2005; Zimmerli, Steinemann, \& Braun, 2003). The relative lack of literature addressing VLABs for general- and special- purpose software applications supporting broad curricula outside science and engineering may be attributed to a lack of off-the-shelf VLAB software and the need for specialized technical skills to construct such labs (Ma \& Nickerson, 2006).

Interest in VLABs arises for several reasons including general interest in supporting distance education, potential for resource sharing and cost savings, and potential for improved educational outcomes. The latter issue is widely debated in the literature with many articles citing evidence of comparative advantage for PLABs and others citing evidence of comparative advantage for VLABs. The conflict among published results can be attributed to many factors including differences in VLAB definition, study scope and methods, field of application, and suitability of labbased work to specific educational objectives. Based on a broad survey of related literature, Ma and Nickerson (2006) argue that VLABs are well-suited to supporting educational objectives concerned with developing professional skills and conceptual understanding.

Our motivation to develop a VLAB was primarily driven by practical concerns of accessibility, cost, and support of in-class computer use. We take no position on the current debate over the relative efficacy of PLABs and VLABs, though we do report some student perceptions that add additional fuel to that fire. We do note that much of our VLAB usage falls within the areas of professional skills and conceptual understanding, which may explain the generally positive perceptions reported by students and our own conclusions.

\section{Computer Lab Evolution}

\section{Before the VLAB}

Prior to VLAB implementation in Fall 2006, our school operated two PLABs in adjacent rooms supporting approximately 1600 enrolled students. The larger room functioned exclusively as a PLAB and contained 64 Windows XP workstations and multiple high speed printers. The smaller room contained 42 Windows XP workstations and functioned as both a computer classroom when needed and a PLAB when not used for classes. Both PLABs were open 16 hours per day on weekdays and 12 hours per day on weekends.

General-purpose application software installed in the PLABs included Microsoft Office Professional 2003, Adobe Acrobat Reader, and secure shell (SSH) and secure file transfer protocol (SFTP) clients. Specialized application software supporting advanced courses included:

- SPSS - Used in many advanced classes in marketing and finance

- Business Plan Pro - Used in classes covering business strategy and used outside of the classroom to support an annual business planning competition

- Oracle JDeveloper - Used as a programming environment in information systems classes

- Oracle SQL*Plus - Used as a database management interface in information systems classes

- A custom finance software package for bidding

- VMware - Used in courses in computer security and system/network administration

Some of the more expensive application software was installed only in the smaller PLAB to reduce licensing costs. 


\section{The Mobile Initiative}

In late 2004 the school undertook a strategic initiative that expanded the scope of its computing capabilities beyond the then existing PLABs to all school classrooms and common areas. Dubbed the "mobile initiative," the goal was to modernize curriculum content and to immerse students in the computer- and communication-intensive nature of modern business. Instructors were encouraged to employ mobile computers for assignments and during regular class periods, while students were strongly encouraged to purchase laptop or tablet computers and bring them to all classes. Intel Corporation donated wireless access points to support the initiative.

To ease the transition, a class on wheels (COWs) program was implemented for three semesters. The program delivered up to 96 school-owned laptop computers to classrooms as needed. Faculty use of computers in the classroom and student ownership of portable computers gradually increased. At the same time, PLAB utilization leveled off and eventually started to decline.

Several lessons were learned during the COWs program, including:

- Faculty were able to successfully employ computing technology in many classes during oncampus face-to-face class periods

- Student comfort with the technology was relatively high but many students needed technical support services

- Variation in software and hardware configuration among student computers and the COWs computers sometimes created problems within the classroom

- Specialized application software used in some classes was too resource-hungry to execute on typical student computers with acceptable performance levels

The latter two points deserve special emphasis since they were two of the most significant factors motivating our implementation of the VLAB and have been noted by others (\& Oblinger, 2007). Variation in computer configuration during in-class computer-based exercises created learning barriers and instructional inefficiencies. For example, following an instructor as he or she "pointed and clicked" through a spreadsheet exercise was quite difficult if some students had Macs and others had PCs. Even if all students had PCs with Windows and Excel installed, variations in Windows and Excel versions, desktop and toolbar configuration, and the presence or absence of "add ins" created problems.

Further difficulties ensued when hardware capability varied widely among student computers (many students preferred to use their own laptops). For example, one student might complete a task in thirty seconds, another student might complete the same task in four minutes, and yet another student might "lock up" their machine due to virtual memory thrashing. In short, if an instructor wanted to teach class content rather than troubleshoot the installation and configuration of software on student computers, a consistent hardware, operating system, application software, and user interface was needed.

Specialized application software used in advanced courses proved especially challenging. Although some software, such as SPSS, was available to students at reduced cost, any software costs were an invitation to software piracy with potential liability to students and the school. Student versions of some software packages lacked key features or were otherwise restricted. Further, the cost of required hardware was beyond the means of many students. Reasonable performance when executing software development tools and virtual machine software typically required hardware 2-3 times as powerful as that available in a basic laptop computer. Installation and maintenance were also beyond the capabilities of many students due to complex dependencies on operating system components (e.g., extensible markup language (XML) and .NET), sup- 
porting software (e.g., a Java Runtime Environment), and configuration (e.g., environment variables, search paths, and directory and file access permissions).

The most extreme example of these challenges was encountered in advanced classes in computer security and system/network administration using VMware Workstation. VMware enables users to create virtual machines and virtual networks - software emulations of computer hardware systems and of physical networks that connect them. The power to emulate multiple computer systems and networks came at a steep price in software cost, required hardware resources, and configuration and operational complexity. Further, some of the exercises performed by students with VMware exposed their computers and the school network to potential hazards including viruses, worms, and misconfigured network services (Bullers, Burd, \& Seazzu, 2006). At least one other school has addressed these issues by outsourcing a VLAB dedicated to system administration courses (Hardaway, Hogan, \& Mathieu, 2005).

In sum, increasing student laptop ownership reduced but did not eliminate the need for schoolprovided computers. School-provided computers were still needed whenever a consistent operational platform, expensive or complex software, powerful hardware, or a "safe" execution environment were required to support learning inside and outside the classroom.

Thus, the school was faced with the challenge of how to support the full range of computing services for the curriculum and for students in the mobile era. Supporting the COWS and two PLABs consumed most of the resources that funded student computing. The school needed to decide how best to deploy resources to support the changing nature of classroom and student computing. The key components of the chosen plan were:

- Closing one PLAB and reallocating its resources

- Creating a student technical services center

- Creating a laptop loan program for students

- Creating a VLAB

The remainder of this paper will concentrate on the VLAB portion of that plan as implemented in Fall 2006.

\section{Developing the VLAB}

The options that we considered for implementing the VLAB included repurposing existing workstations from the soon-to-be-closed PLAB, purchasing new rack mount servers, and deploying virtual machines. Existing workstations were well within their useful life and the school had current site licenses for all required software. Implementing a Citrix-based VLAB for the same number of users using three rack-mounted servers was estimated to cost approximately $\$ 60,000$ for server hardware and $\$ 40,000$ for software. Use of VMware with rack-mount servers raised software costs and necessitated custom development for an interface to load and start VMware workstation images on demand (VMware has since released the VMware Lab Manager product that performs this function). All options had similar requirements for physical space and supporting network capacity and equipment. Repurposing existing workstations was the chosen alternative because it required fewer new resources and because the administrative burden was similar to that of a PLAB. The primary trade-off was reduced scalability, though we have not yet needed to expand the VLAB beyond its original number of users.

We allocated part of the space occupied by the former PLAB to host the repurposed workstations and supporting equipment (see Figure 2). 42 workstations were mounted on racks and connected to a set of keyboard-video-mouse (KVM) switches, network switches, and uninterruptible power supplies. (The original VLAB workstations have since been upgraded to those depicted in Figure 
2.) The left rack houses (top to bottom) network switches, KVM switches, shared I/O devices, SAN server, and SAN UPSs. The right rack houses half of the VLAB workstations and their UPSs. An identical workstation rack is out of frame to the left.

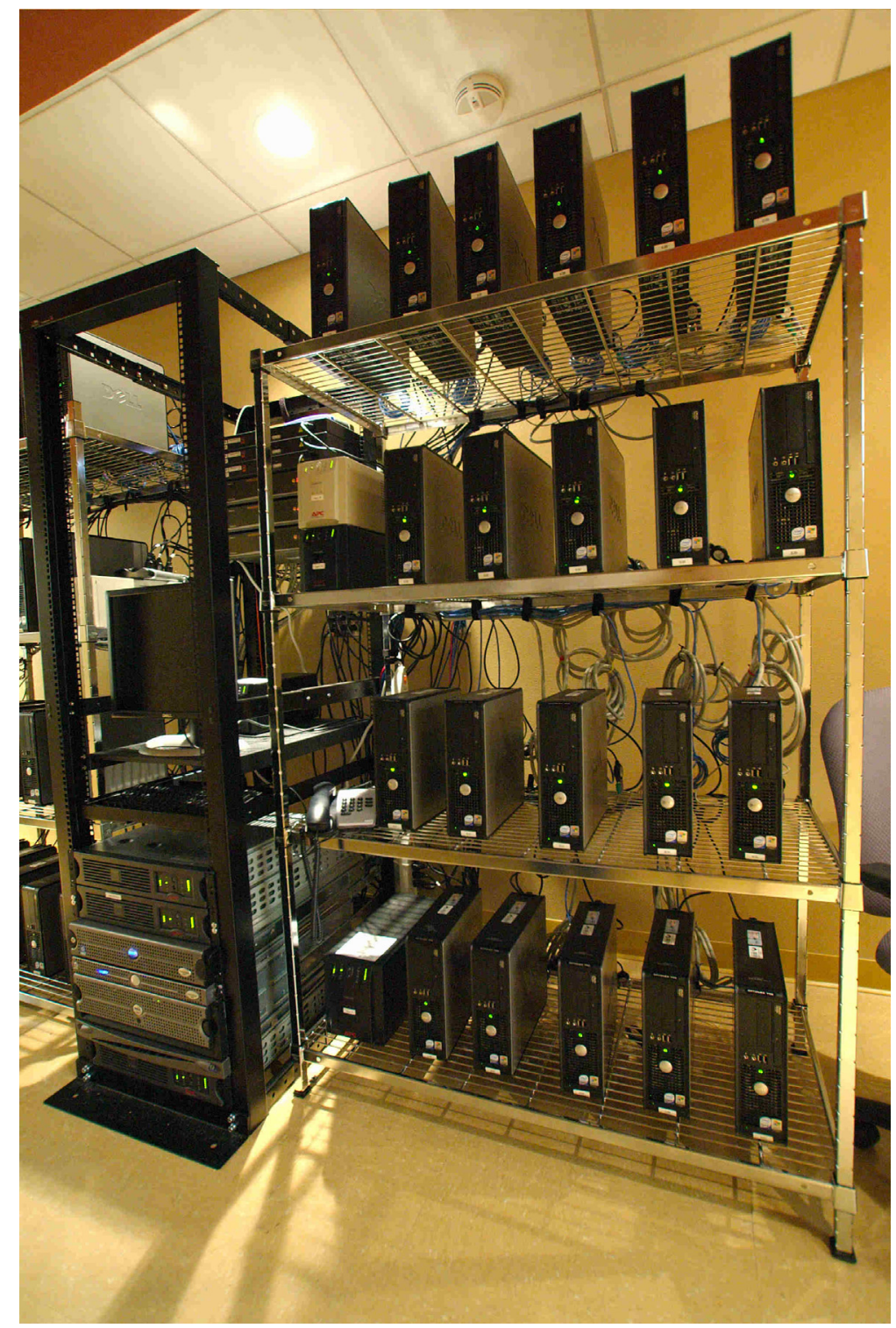

Figure 2. VLAB physical configuration.

The required floor space for all equipment and racks, including front and rear access, is approximately $6 \times 15$ feet. The space needed to house 42 VLAB workstations is approximately onetwenty-fifth the space required for the same number of PLAB workstations due to eliminating monitors, keyboards, and space for furniture and student access. Most of the remaining space from the decommissioned PLAB was devoted to a new student technology services center (STSC) that provided technical support, loaner laptops, and access to several workstations connected to high-speed printers.

\section{VLAB Configuration and Access Control}

The previous and current PLAB workstations were supported and controlled by servers implementing Microsoft Active Directory, Microsoft Remote Installation Services, Symantec Anti- 
virus, and a Nokia Checkpoint firewall. The servers control various aspects of a workstation's configuration and operation including:

- Operating system configuration including available utilities, patch installation, desktop settings, and user ability (or lack thereof) to perform functions such as accessing printers, installing device drivers, and executing command line functions

- Application software installation and configuration

- Security settings including file system permissions, antiviral scans, and protection from malware

The existing server infrastructure configuration was modified to implement two different workstation configurations: one for PLAB workstations and the other for VLAB workstations. For the VLAB workstations, the most important configuration change was to enable Microsoft Remote Desktop Services. Other configuration differences are described in the next section.

To simplify access to the VLAB workstations, an in-house developer created a Web-based interface (see Figure 3 ) on a small dedicated web server. The interface includes embedded programs written in $\mathrm{C}$ and VBScript to generate the web page from text configuration files and to update its content. One VBScript polls the 42 workstations 3 times per minute to determine which are available and which are in use and updates the web page icons and text as appropriate. When a user clicks on an available system, a script initiates a remote desktop connection from the users' computer directly to the chosen workstation.

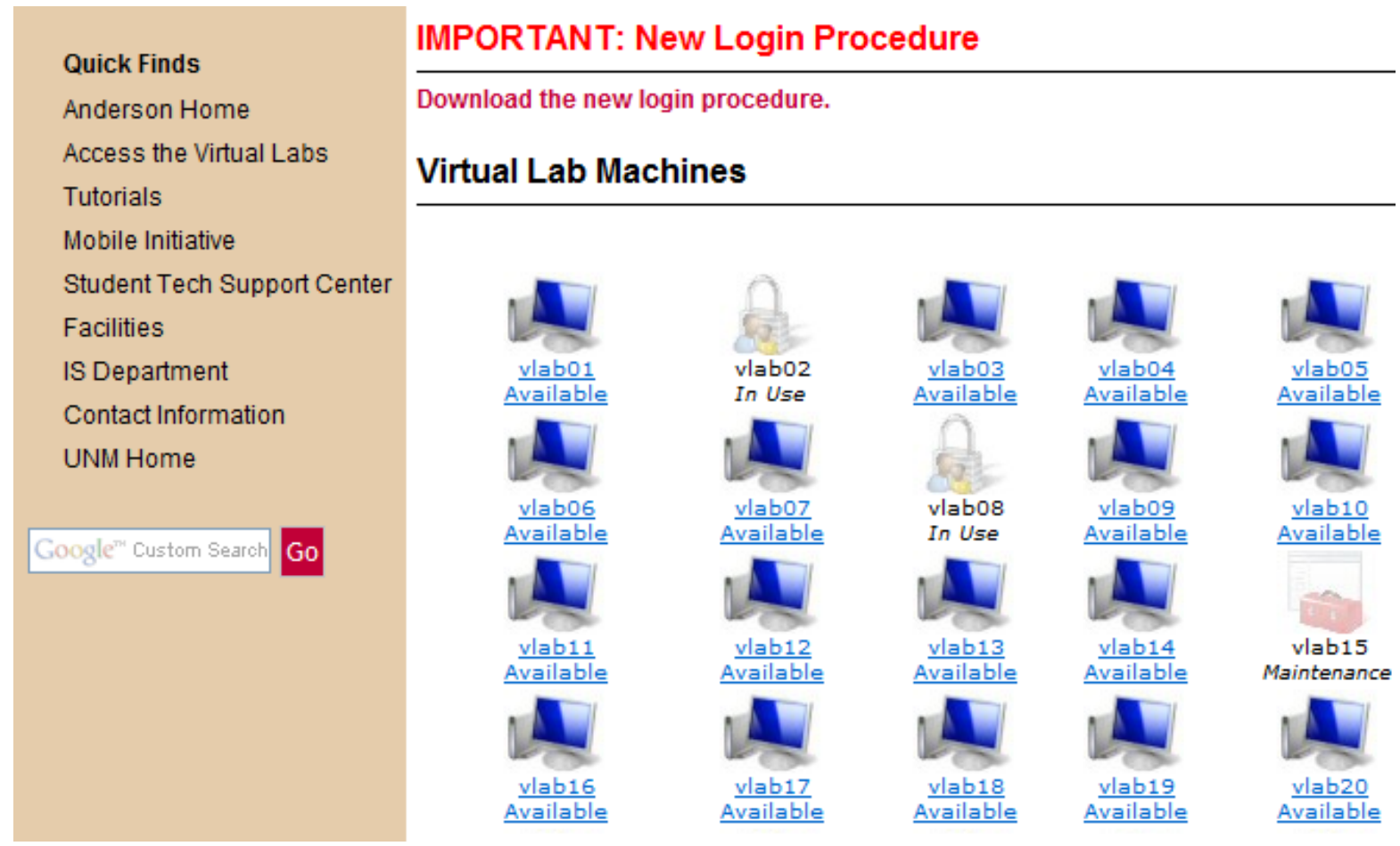

Figure 3. Web page for accessing VLAB computers.

Network capacity was not a significant issue in deploying our VLAB since the school operates in a relatively bandwidth-rich environment. The university and school have gigabit backbone networks and switches and the university has two T3 internet connections, which are rarely saturated. The VLAB workstations are connected to the school backbone network via gigabit interfaces and dedicated switches. Wireless access points in the school have 100 megabit connections 
to the school firewall and backbone network. Each active VLAB connection consumes approximately $30 \mathrm{Kbps}$ of streaming bandwidth (Shields, 2004). Periodic monitoring of VLAB performance has yet to reveal any bandwidth-related performance problems for user I/O.

\section{PLAB and VLAB Configuration Differences}

Differences in software-related configuration between the PLAB and VLAB can be classified into the following categories:

- File storage and access

- Printing

- Expensive specialized application software

- Virtual machine software

- Network access

In the PLAB, students could use, store, and transport files in several ways including removable storage devices, email attachments, a web-based briefcase, and SFTP. They can also access email, web-based briefcase, and SFTP-accessible storage services on shared University servers. For the VLAB workstations, lack of physical access precludes using removable storage devices, thus eliminating the most convenient form of file management for lab users.

Neither PLAB nor VLAB workstations have direct access to printers. This limitation was intentionally implemented to reduce paper and toner usage. Instead, six workstations in the STSC are dedicated to printing. To print documents, students must either physically carry files to those workstations on removable media or copy files to temporary directories from their web briefcase or via SFTP. Although the printer configuration is the same for PLAB and VLAB workstations, printing is effectively more difficult from VLAB workstations due to users' inability to access removable storage devices.

SPSS and Business Plan Pro were removed from the PLAB and made available only in the VLAB to reduce licensing costs and to make them accessible from classrooms and other remote locations. VMware was also installed only in the VLAB. This saved on licensing costs but also made it easier to solve a problem that existed in the PLAB - insufficient workstation-independent storage for VMware image files.

VMware image files encapsulate the hard disk content of a virtual machine and range from 2-10 GBytes depending on the client operating system and installed software and services. Students in networking, security, and system administration classes often use multiple images while completing an assignment. In the old PLAB, limited disk storage, network capacity, workstation security configuration, and the relatively small capacity of removable storage devices made it difficult or impossible to move VMware image files from one workstation to another. Thus, students were limited to a single workstation for the duration of the semester, which created problems of image file accessibility when a needed machine was being used by another student. Image files were also susceptible to workstation failure, which was partially mitigated by providing some backup space on a dedicated backup server. But access to the server via file transfer protocol (FTP) was very slow given the limitations of the workstation network interfaces, the general-purpose network, and the backup server.

We had earlier considered installing a storage area network (SAN) server in one of the PLABs to store and quickly access virtual machine images but the distance to be spanned raised potential reliability and performance problems. Within a VLAB, close physical proximity of workstations 
simplifies SAN interconnections. It also minimizes the possibility of errors due to tripping over cables and similar events. Thus, when the VLAB was implemented we also installed a SAN.

VLAB workstation access to network resources was limited to network addresses within the university domain. The purpose of this restriction was to minimize the potential spread of and susceptibility to malware. The nature of many VMware assignments (e.g., testing operating system and firewall security configuration) makes those machines especially vulnerable to viruses and other malicious attacks. Once compromised, a VLAB workstation could spread the attack to the university network and beyond. Limiting network access to the university domain represents a compromise between security and usability. Without access to the university domain VLAB users would be unable to save files via email, FTP, or their web briefcase and would thus also be prevented from printing.

\section{PLABs and VLABs Compared}

This section of the paper will compare VLABs and PLABs in six areas. Parts of our comparisons are based on a survey of students administered during April 2007. We selected survey respondents based on their enrollment in courses that used software installed on the VLAB computers. Responses were considered valid if the student had used both the PLAB and the VLAB since their enrollment at the school. Table 1 summarizes self-reported characteristics of the valid respondents. Table 2 summarizes their responses to VLAB attitudes and use questions. Correlation statistics and a related discussion are included in the Appendix.

Table 1. Summary of respondent characteristics*

\begin{tabular}{|c|c|}
\hline Characteristic & Value(s) \\
\hline Number of respondents & 112 \\
\hline Age & Range 21-54, median 23 \\
\hline Gender & $50 \%$ male, $46 \%$ female \\
\hline Degree Program & $\begin{array}{cc}\text { BBA } & 66 \% \\
\text { MBA } & 18 \% \\
\text { M. Accounting } & 8 \% \\
\text { Other } & 4 \% \\
\text { None } & 2 \%\end{array}$ \\
\hline Technical concentration & $29 \%$ \\
\hline Laptop ownership & $81 \%$ \\
\hline Laptop checkout from school & $\begin{array}{cc}\text { Frequently } & 8 \% \\
\text { Occasionally } & 12 \% \\
\text { Seldom } & 4 \% \\
\text { Rarely or Never } & 72 \% \\
\end{array}$ \\
\hline $\mathrm{Mac} / \mathrm{PC}$ & Mac: 11\% PC: $87 \%$ \\
\hline Computer ability self-assessment & $\begin{array}{ll}\text { Novice } & 2 \% \\
\text { Some Ability } & 5 \% \\
\text { Significant Ability } & 45 \% \\
\text { "Power User" } & 45 \% \\
\end{array}$ \\
\hline
\end{tabular}

*All percentage results are rounded to the nearest whole number. The results in some categories do not total $100 \%$ due to rounding and to some respondents providing no answer or multiple answers to a single question. Students with multiple concentrations were counted as "technical concentration" if any of their concentrations were information systems, computer science, computer engineering, or a similar field. 
Table 2. Summary of responses to questions about VLAB attitudes and use

\begin{tabular}{|c|c|c|c|c|c|}
\hline Question & \multicolumn{5}{|c|}{ Responses } \\
\hline $\begin{array}{l}\text { What software appli- } \\
\text { cations have you used } \\
\text { on the VLAB }{ }^{*} \text { sys- } \\
\text { tems (circle all that } \\
\text { apply)? }\end{array}$ & $\begin{array}{l}\text { Web browser } \\
50 \%\end{array}$ & $\begin{array}{l}\text { MS Office } \\
45 \%\end{array}$ & $\begin{array}{l}\text { Programming } \\
\text { and VMware } \\
50 \%\end{array}$ & $\begin{array}{l}\text { Statistics } \\
51 \%\end{array}$ & $\begin{array}{l}\text { Accounting, } \\
\text { finance, busi- } \\
\text { ness planning } \\
2 \%\end{array}$ \\
\hline $\begin{array}{l}\text { Compared to a } \\
\text { PLAB, I think that } \\
\text { using the VLAB is: }\end{array}$ & $\begin{array}{l}\text { Much more } \\
\text { difficult } \\
8 \%\end{array}$ & $\begin{array}{l}\text { Somewhat } \\
\text { more difficult } \\
42 \%\end{array}$ & $\begin{array}{l}\text { About as dif- } \\
\text { ficult } \\
31 \%\end{array}$ & $\begin{array}{l}\text { Somewhat } \\
\text { less difficult } \\
12 \%\end{array}$ & $\begin{array}{l}\text { Much less dif- } \\
\text { ficult } \\
5 \%\end{array}$ \\
\hline $\begin{array}{l}\text { Compared to a } \\
\text { PLAB, I think that } \\
\text { using the VLAB is: }\end{array}$ & $\begin{array}{l}\text { Much more } \\
\text { convenient }\end{array}$ & $\begin{array}{l}\text { Somewhat } \\
\text { more conven- } \\
\text { ient } \\
32 \%\end{array}$ & $\begin{array}{l}\text { About as con- } \\
\text { venient } \\
20 \%\end{array}$ & $\begin{array}{l}\text { Somewhat } \\
\text { less conven- } \\
\text { ient } \\
12 \%\end{array}$ & $\begin{array}{l}\text { Much less } \\
\text { convenient }\end{array}$ \\
\hline $\begin{array}{l}\text { Is the VLAB a valu- } \\
\text { able addition to } \\
\text { school computer fa- } \\
\text { cilities? }\end{array}$ & $\begin{array}{l}\text { Yes } \\
95 \%\end{array}$ & $\begin{array}{l}\text { No } \\
5 \%\end{array}$ & & & \\
\hline $\begin{array}{l}\text { Have you been able } \\
\text { to access VLAB sys- } \\
\text { tems when you } \\
\text { needed them? }\end{array}$ & $\begin{array}{l}\text { Almost al- } \\
\text { ways } \\
56 \%\end{array}$ & $\begin{array}{l}\text { Usually } \\
39 \%\end{array}$ & $\begin{array}{l}\text { Seldom } \\
4 \%\end{array}$ & $\begin{array}{l}\text { Rarely or } \\
\text { Never } \\
0 \%\end{array}$ & \\
\hline $\begin{array}{l}\text { From which locations } \\
\text { have you accessed the } \\
\text { VLAB (circle all that } \\
\text { apply)? }\end{array}$ & 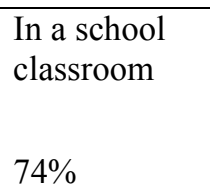 & $\begin{array}{l}\text { At school but } \\
\text { not in a class- } \\
\text { room } \\
45 \%\end{array}$ & $\begin{array}{l}\text { Elsewhere on } \\
\text { the university } \\
\text { campus } \\
40 \%\end{array}$ & $\begin{array}{l}\text { Home } \\
76 \%\end{array}$ & $\begin{array}{l}\text { Work and } \\
\text { while traveling } \\
\text { out-of-town } \\
26 \%\end{array}$ \\
\hline $\begin{array}{l}\text { What device types } \\
\text { have you used to ac- } \\
\text { cess the VLAB (circle } \\
\text { all that apply)? }\end{array}$ & $\begin{array}{l}\text { Laptop com- } \\
\text { puter } \\
86 \%\end{array}$ & $\begin{array}{l}\text { Tablet com- } \\
\text { puter } \\
4 \%\end{array}$ & $\begin{array}{l}\text { Non-portable } \\
\text { computer } \\
70 \%\end{array}$ & 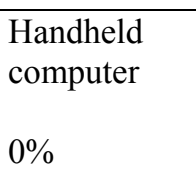 & $\begin{array}{l}\begin{array}{l}\text { Smart cell } \\
\text { phone }\end{array} \\
1 \%\end{array}$ \\
\hline $\begin{array}{l}\text { When do you access } \\
\text { the VLAB (circle all } \\
\text { that apply)? }\end{array}$ & $\begin{array}{l}\text { Daytime } \\
75 \%\end{array}$ & $\begin{array}{l}\text { Evening } \\
82 \%\end{array}$ & $\begin{array}{l}\text { Late at night } \\
41 \%\end{array}$ & $\begin{array}{l}\text { Weekdays } \\
50 \%\end{array}$ & $\begin{array}{l}\text { Weekends } \\
47 \%\end{array}$ \\
\hline $\begin{array}{l}\text { Are there tasks or } \\
\text { software applications } \\
\text { for which you prefer } \\
\text { a PLAB to a VLAB? }\end{array}$ & $\begin{array}{l}\text { Yes } \\
40 \%\end{array}$ & $\begin{array}{l}\text { No } \\
60 \%\end{array}$ & & & \\
\hline $\begin{array}{l}\text { Are there tasks or } \\
\text { software applications } \\
\text { for which you prefer } \\
\text { a VLAB to a PLAB? }\end{array}$ & $\begin{array}{l}\text { Yes } \\
31 \%\end{array}$ & $\begin{array}{l}\text { No } \\
69 \%\end{array}$ & & & \\
\hline
\end{tabular}

*The acronyms VLAB and PLAB were fully spelled out in the survey questions and the first page provided brief definitions and included a screen capture similar to Figure 3.

\section{Accessibility and Availability}

Students must be physically present at a PLAB location during hours when the facility is open. In contrast, a VLAB is accessible 24:7 from any Internet-connected computing device with suffi- 
cient bandwidth (DSL is sufficient for most applications that don't heavily use high-resolution graphics or motion video) and appropriate access software (a Web browser and the Microsoft Remote Desktop client with our VLAB implementation). Either lab type provides access to specialized software applications not installed on student computers, though the VLAB extends access to these resources. Access and availability are perhaps especially important to our student population since few of them live on or near campus and the majority of them work part- or fulltime.

Common sense assumptions about the accessibility and availability of the VLAB are supported by the student survey results. $95 \%$ of respondents considered the VLAB a valuable addition to school computing resources and the same percentage were able to almost always or usually access the VLAB systems when needed. $63 \%$ of respondents considered the VLAB much more or somewhat more convenient than a PLAB. Survey responses also show that access locations and times were widely distributed. These results are consistent with those reported by other researchers (Canfora, Daponte, \& Rapuano, 2004; Cooper, Donnelly, \& Ferreira, 2002).

Survey results do show a few concerns about convenience and variability in overall satisfaction among different groups of students. Although the majority of respondents thought the VLAB was more convenient $17 \%$ expressed the opposite opinion. Positive attitudes toward the VLAB are positively correlated with graduate vs. undergraduate students and technical vs. non-technical concentrations. Though not shown by the data in the Appendix, the more important correlation is technical concentration since graduate students surveyed were more likely to have technical concentrations than undergraduates.

PLABs and VLABs have similar dependencies on power and network infrastructure and the availability of both lab types can be compromised by infrastructure failures. For both lab types, local network failures disable workstations by preventing contact with needed support services (e.g., Active Directory). Internet-related network failures prevent all access to a VLAB from outside the school or university network. For a PLAB, Internet-related network failures disable only Internet-based applications - local applications such as Microsoft Office continue to function.

\section{Usability and Task Support}

Responses to the first question in Table 2 show that software use was distributed widely across both general- and special-purpose applications in both lab types, thus providing ample basis for comparative evaluations. Approximately one third of all respondents expressed preference for one lab type over the other for some specific tasks. Also, $50 \%$ of respondents thought that using the VLAB was much more or somewhat more difficult than the PLAB. Difficulty, though not a direct measure of accessibility, is one possible barrier to access. Difficulty also has cost and training implications as described in the next section.

Fifty-six written comments from students expressing their reasons for VLAB or PLAB preference were analyzed to derive the preference summaries below, listed in descending order of frequency:

- Printing and file transfer: These issues are interrelated and both are a byproduct of lack of physical access. As described earlier, students using VLAB machines must transfer files to another computer via FTP or email attachment. Thus, saving and printing documents is a more cumbersome process in a VLAB.

- Video performance: Many students noted slow responses for web-browsing and graphically-intensive applications. Specific examples included problems with large images and rapidly changing graphical content. These issues are a byproduct of updating display content across computers over a network connection rather than between a computer and a display device over a higher-speed dedicated video connection. 
- Support and environment: Issues in this category include availability of support staff and support for workgroups. Support staff members are physically present in a PLAB and generally able to provide immediate and direct assistance to students. Also, the physical layout of our PLAB provides space for student groups to meet and work together on group assignments.

Students who preferred the VLAB for one or more tasks cited two primary reasons:

- Convenience: Approximately $23 \%$ of the written comments elaborated on the comparative convenience (accessibility and availability) of the VLAB. Though not directly related to any curriculum-oriented tasks, these comments provide strong reinforcement to the direct questions on convenience and perceived value.

- System and network administration: Students in computer security and system administration classes (MGMT 636 and 639) cited the availability of virtual machine software and the ability to complete complex class assignments as important VLAB advantages.

The generalizability of some student perceptions, including printing, file transfer, and support for system and network administration tasks, is obviously colored by the specific configuration differences in our PLAB and VLAB. These issues could be differently handled in other VLAB implementations thus mitigating some of the specific concerns expressed by our students.

On the other hand, perceptions of usability related to convenience, video performance, and support for group work are broadly applicable. Convenience is an advantage cited by students in other studies including Corter, Nickerson, Esche, and Chassapis (2004) and Ogot, Elliott, and Glumac (2003). Other studies have identified support for collaborative effort as a key issue in VLABs (Mann \& Parashar, 2002). But it isn't clear whether collaboration support needs to be designed into the VLAB architecture or whether students should be left to design their own collaboration approaches (e.g., working as a group in front of one or more laptops connected to a VLAB or engaging in a chat session in a separate window of their laptop). As noted by Ma and Nickerson (2006, p.13), "It may be that students using remote laboratories will find different ways of collaborating, and the mode of collaboration they choose may affect what they learn from the laboratory experience."

\section{Training}

When considering training there are two types of users to examine, the instructor and the student. For the instructor, the transition from a single system in their office or in a classroom to a PLAB is relatively straightforward. The primary differences to be overcome include desktop layout, menu organization and content, and restrictions on where user files may be stored. Students have the same set of differences to overcome but they do so once and then reuse that knowledge over many semesters and courses. On-site assistance provides immediate support to ease the transition.

With VLABs, another instructor or IT staff member has to familiarize the teaching instructor with accessing resources remotely. This requires both a technical and a conceptual preparation. Once this step is completed the teaching instructor must relay this information to the students. In our experience, students often require multiple presentations to fully assimilate the process. Thus, parts of multiple class sessions are spent demonstrating how to access VLABs.

One successful alternative has been the use of an on-demand training module accessible from the VLAB access web page. The module is a video recording of all the actions taken by a user to access and use VLABs accompanied by an audio commentary explaining how and why each action was taken. 


\section{Security}

Security issues can be separated into physical and non-physical aspects. Because physical access to PLAB machines is controlled, limited to registered students, and monitored by on-site staff, exposure to theft and physical attack is relatively low. But that risk exposure is clearly greater than for a VLAB where hardware is behind locked doors with no public access.

PLABs and VLABs share many non-physical security requirements including the need to restrict access to important files, prevent unauthorized changes to operating system and application configuration, and prevent viruses, spyware, and other malicious attacks. Our PLAB workstations employ a security configuration with following characteristics:

- Generic accounts with blank passwords and limited privileges

- Disabled remote logon

- Restrictions on loading unauthorized executables and booting from removable storage devices

- Restrictions on file system access and local file storage

- Automatic antiviral and related scanning of downloaded files and removable storage devices

The remotely-accessible nature of VLAB machines required deviations from our PLAB security configuration in the areas of accounts, passwords, and remote logon permissions. Our VLAB workstations use a different generic account than the PLAB computers. The account requires a password, which is given to faculty members only after they have been trained in the use of the VLAB. The generic VLAB account is used by all students except those enrolled in IT security and system administration classes.

A separate set of accounts and passwords are assigned to specific students in classes that use VMware. These accounts have the same privileges as the generic VLAB account except for the added ability to access the SAN to store and retrieve VMware images. Account-specific permissions prevent one student from accessing or altering the images of another.

To enable student access, remote logon via Microsoft remote desktop protocol (RDP) is enabled on VLAB machines. The RDP port was changed from the default 3389 to avoid current or future malicious attacks on that well-known port. This in turn resulted in some students not having access in specific environments, namely work, where the employer's firewall blocked the outbound traffic on the new port. Port scanning is disabled within the school network to avoid external discovery of this and other remapped ports. None-the-less, even a "hidden" ability to access a VLAB workstation from external locations presents a security risk not present in the PLAB.

\section{Administration}

Both PLABs and VLABs require installation and maintenance of system and applications software, hardware maintenance, and implementing and monitoring appropriate security and other controls. Though there are differences in some administrative areas such as security configuration, most administrative effort in these areas is similar across lab types. But an organization that chooses to support both lab types does face an increased administrative burden due to the added complexity of having two lab types. Quantifying that burden and determining its significance within the milieu of computer- and network-related administrative tasks of a typical school or university is a difficult task.

There are two areas of distinct administrative difference across lab types - access and personnel. As described earlier, access to VLAB workstations is controlled through a web-based interface which must be developed, administered, and maintained. Other VLABs might employ different 
technological approaches but the basic problem of enabling and administering remote access cannot be avoided. In contrast, access to a PLAB is physical which eliminates the need for a web site or other access method but adds administrative overhead for monitoring and physical security. A monitored PLAB must be staffed during open hours to provide security and technical support and those staff members must be hired, scheduled, and supervised. In a VLAB, there is no corresponding security need driving personnel costs but there may still be a need for technical support staff accessible by telephone, email, or Internet chat.

\section{Cost}

Our PLAB and VLAB incur similar hardware and software costs and require comparable technical and infrastructure support. Hardware and software costs are less comparable for VLABs that employ rack-mounted servers and terminal services or virtual machine software to emulate single user workstations. Hardware costs for our VLAB are detailed in Table 3. Note that some of the cost categories, such as workstations and network switches, required no initial funds since the hardware was repurposed from a former PLAB. A single monitor, keyboard, and mouse are shared among the 42 workstations and the servers via the KVM switches and cabling.

Table 3. Hardware costs for a 42 station VLAB

\begin{tabular}{|l|r|}
\hline \multicolumn{1}{|c|}{ Description } & \multicolumn{1}{c|}{ Cost } \\
\hline VLAB computers (42 @ \$1500) & $\$ 63,000$ \\
\hline Storage server & $\$ 35,000$ \\
\hline Uninterruptable power supplies (8@ @ \$600) & $\$ 4,800$ \\
\hline Network switches (3 @ \$1000) & $\$ 3,000$ \\
\hline Web server & $\$ 1,500$ \\
\hline Racks & $\$ 1,500$ \\
\hline KVM switches and cabling & $\$ 1,200$ \\
\hline Video monitor, keyboard, and mouse & $\$ 300$ \\
\hline Total Cost & $\$ \mathbf{1 1 0 , 3 0 0}$ \\
\hline
\end{tabular}

Table 4 summarizes cost comparisons among our PLAB and VLAB (negative VLAB cost advantages are shown in parentheses). Cost categories with the largest differences include personnel, floor space, workstation peripherals, and furnishings. Summing the annual cost across categories generates a VLAB cost advantage of $\$ 89,920$ for our VLAB with 42 workstations. If the VLAB were scaled up to 75,100 , or 150 workstations that cost advantage would increase to $\$ 124,158$, $\$ 200,200$, or $\$ 252,083$, respectively. Cost does not scale linearly with size since some cost categories such as personnel and servers are represented as step functions. The cost difference between PLABs and VLABs depends on many assumptions, some of which are detailed below, and the most significant of which concern staffing and technical support. 
Table 4. PLAB and VLAB cost comparisons

\begin{tabular}{|c|c|c|c|c|c|}
\hline $\begin{array}{c}\text { Cost } \\
\text { Category }\end{array}$ & PLAB & VLAB & $\begin{array}{c}\text { VLAB } \\
\text { Cost } \\
\text { Advantage }\end{array}$ & $\begin{array}{c}\text { Amortizatio } \\
\text { n Period } \\
\text { (Years) }\end{array}$ & $\begin{array}{c}\text { Annual } \\
\text { VLAB Cost } \\
\text { Advantage }\end{array}$ \\
\hline $\begin{array}{l}\text { Workstations } \\
\text { - base }\end{array}$ & \multicolumn{2}{|l|}{ Same } & None & & None \\
\hline $\begin{array}{l}\text { Workstations } \\
\text { - peripherals }\end{array}$ & $\begin{array}{l}\text { Monitor, keyboard, } \\
\text { mouse, and remov- } \\
\text { able storage for each } \\
\text { seat }(\$ 12,600)\end{array}$ & $\begin{array}{l}\text { One monitor, key- } \\
\text { board, and mouse } \\
\text { shared using KVM } \\
\text { switches }(\$ 1500)\end{array}$ & $\$ 11,100$ & 3 & $\$ 3700$ \\
\hline $\begin{array}{l}\text { Network } \\
\text { hardware and } \\
\text { cabling }\end{array}$ & \multicolumn{2}{|l|}{ Same } & None & & None \\
\hline Software & \multicolumn{2}{|l|}{ Same } & None & & None \\
\hline Furnishings & $\begin{array}{l}\text { Desks and chairs } \\
\text { (estimated cost } \$ 150 \\
\text { per workstation) }\end{array}$ & $\begin{array}{l}\text { Racks (estimated cost } \\
\$ 1500)\end{array}$ & $\$ 4800$ & 6 & $\$ 800$ \\
\hline UPSs & None & $\begin{array}{l}1 \text { per } 6 \text { workstations } \\
\text { (estimated cost } \$ 600 \\
\text { each) }\end{array}$ & $(\$ 4800)$ & 3 & $(\$ 1600)$ \\
\hline $\begin{array}{l}\text { Lab opera- } \\
\text { tions staff }\end{array}$ & $\begin{array}{l}\text { One person to moni- } \\
\text { tor facility (assume } \\
\$ 10 \text { per hour, } 5000 \\
\text { hours per year) }\end{array}$ & None required & $\$ 50,000$ & 1 & $\$ 50,000$ \\
\hline Servers & $\begin{array}{l}\text { Active Directory, } \\
\text { DNS/DHCP, Fire- } \\
\text { wall, etc. }\end{array}$ & $\begin{array}{l}\text { Same with addition } \\
\text { of web sever (esti- } \\
\text { mated cost } \$ 1500) \text { to } \\
\text { control access. }\end{array}$ & $(\$ 1500)$ & 3 & $(\$ 500)$ \\
\hline $\begin{array}{l}\text { Development } \\
\text { and adminis- } \\
\text { trative staff }\end{array}$ & $\begin{array}{l}\text { OS, security, appli- } \\
\text { cations, etc. }\end{array}$ & $\begin{array}{l}\text { Same with addition } \\
\text { of initial develop- } \\
\text { ment of access web } \\
\text { site }\end{array}$ & $(\$ 4000)$ & 5 & $(\$ 800)$ \\
\hline $\begin{array}{l}\text { Development } \\
\text { and adminis- } \\
\text { trative staff }\end{array}$ & $\begin{array}{l}\text { OS, security, appli- } \\
\text { cations, etc. }\end{array}$ & $\begin{array}{l}\text { Same with addition } \\
\text { of regular mainte- } \\
\text { nance of access web } \\
\text { site }\end{array}$ & $(\$ 2000)$ & 1 & $(\$ 2000)$ \\
\hline Floor space & $\begin{array}{l}\text { Approximately } 50 \\
\text { square feet per } \\
\text { workstation }\end{array}$ & $\begin{array}{l}\text { Approximately } 2 \\
\text { square feet per work- } \\
\text { station }\end{array}$ & $\$ 40,320$ & 1 & $\$ 40,320$ \\
\hline Room utilities & $\begin{array}{l}\text { Lighting, power for } \\
\text { hardware, heat, and } \\
\text { cooling }\end{array}$ & $\begin{array}{l}\text { Minimal lighting and } \\
\text { heating, cooling } \\
\text { needs are reduced } \\
\text { (fewer peripherals } \\
\text { and no body heat) but } \\
\text { concentrated in a } \\
\text { smaller area }\end{array}$ & $\begin{array}{l}\text { None - } \\
\text { assume } \\
\text { cost differ- } \\
\text { ences off- } \\
\text { set }\end{array}$ & & None \\
\hline nnual VLA & $t$ & & & & $\$ 89,920$ \\
\hline
\end{tabular}


Costs for workstation base units, software, and networking are essentially the same for both lab types, though cabling costs are slightly lower for a VLAB due to shorter cable runs. PLABs incur costs for workstation peripherals and furnishings that aren't required for a VLAB. The annual cost differential in these categories depends on both acquisition cost and assumed asset life (amortization period).

PLABs generally require full-time staff to monitor the facility for theft and vandalism and sometimes to provide technical support. Many schools use work-study students as lab monitors thus providing a relatively low labor cost per hour. However, the large number of open PLAB hours yields a considerable annual cost. VLABs do not require monitoring staff, and technical support may or may not be provided (our calculation assumes that it isn't). Note that the annual savings estimate for our VLAB would be reduced to $\$ 39,920$ if technical support were provided to VLAB users for the same number of hours as technical support and monitoring for the PLAB.

The VLAB web-based interface for VLAB access required approximately 1 man-month (160 hours) to develop and continued maintenance of the server and web site is estimated to require one man-week (80 hours per year). Development cost was amortized over five years. Hourly development and maintenance staff costs were estimated at $\$ 25$.

The lack of furnishings, lighting, and other "human-oriented" features makes our VLAB approximately 25 times more space-efficient than the existing PLAB of the same capacity. Quantifying the resulting economic savings is inexact since it depends on actual space costs, opportunity costs for the space savings, and whether alternative student work or meeting space is required when a PLAB is converted to a VLAB. To generate the corresponding estimate in Table 4 we used 42 workstations, the actual space difference between our PLAB and VLAB, and cost figures supplied by the university architect's office for new classroom and general lab construction and maintenance. We summed construction and maintenance costs over thirty years and derived an annualized present value of approximately $\$ 20$ per square foot, which closely approximates the annual rental cost of Class A office space in the surrounding metropolitan area (Ginsberg, 2007). We assumed that no alternate space was required to compensate for lost PLAB space - a valid assumption for our campus given adequate student work and meeting space in existing common areas including our student events center and library.

Costs relating to training and productivity gains or losses are ignored in this cost analysis. Survey-based evidence shows a difference in ease of use, which should result in increased resources requirements for training, some initial or continuing loss in productivity, or both. However, the costs directly attributable to these factors are very difficult to quantify and there is a trade-off among them.

\section{Lessons Learned}

In this section we highlight and summarize some of the more important lessons that we've learned from our experience developing and operating our VLAB.

Student Satisfaction: Students are satisfied with the VLAB primarily due to its convenience and accessibility. That satisfaction is broad-based though it is lower for students with non-technical concentrations. There is a clear need for training and user support, especially for non-technical students to bridge the "satisfaction gap" and improve satisfaction for all students. The user experience in a VLAB should mirror that of a PLAB or student-owned computer to the maximal extent possible. If we were starting over we'd devote greater resources to training, user support, and simplifying tasks such as file transfer and printing.

Disorientation: We've noted that some users become disoriented with the multiple interface layers inherent in a VLAB implementation - users can easily lose their sense of which interface is 
local and which is remote. A common symptom is difficulty deciding which icon (e.g., start button) to click to complete a simple task. This problem is further compounded when users execute virtual machines within a VLAB workstation. This problem is a prime target for additional training and user support resources.

Queuing: There are times, especially near semester end, when VLAB workstations are all in use. Students become frustrated by the lack of a "line" for the next available workstation. We are exploring technology to implement a queuing strategy to address this problem.

Cost: The most significant cost differences among PLABs and VLABs are for space and personnel. The cost differences in Table 4 reflect our actual experience. However, if we were starting over we'd redirect some or all of those cost savings into training and support. In spaceconstrained schools, it may be necessary to redirect some of the space cost savings into alternative work and meeting spaces for students.

Administration and VLAB Implementation: Implementing the VLAB using single-user workstations with software and hardware configurations nearly identical to the PLAB greatly simplified overall administration. There is an additional burden imposed to administer both lab types but the added burden of deploying a VLAB in addition to a PLAB is relatively small if their configurations are similar. Our VLAB approach may not scale well to larger labs. But in our environment it enabled us to deploy a VLAB quickly and with a minimal infusion of new skills and resources.

Security: VLAB computers are more vulnerable than PLAB computers to security problems such as network-based attacks. We expended considerable effort to design appropriate mitigation methods, monitor their effectiveness, and make adjustments - with excellent results. Any school that implements a VLAB should make security planning, implementation, and monitoring a high priority.

\section{References}

Bullers, W. I., Burd, S. D., \& Seazzu, A. (2006, March). Virtual machines - An idea whose time has returned: application to network, and security, and database courses. ACM SIGCSE Bulletin (Inroads), pp. 102-106.

Canfora, G., Daponte, P., \& Rapuano, S. (2004). Remotely accessible laboratory for electronic measurement teaching. Computing Standards and Interfaces, 26(6), 489-499.

Caruso, J. (2007). Highlights of the UW-Madison results from the 2006 ECAR student study. Retrieved May 29, 2007 from http://www.doit.wisc.edu/about/research/UWMadisonECAR2006StudentPres.pdf

Cooper, M., Donnelly, A., \& Ferreira, J. M. (2002). Remote controlled experiments for teaching over the Internet: A comparison of approaches developed in the PEARL project. Proceedings of the ASCILITE Conference 2002. Auckland, New Zealand. UNITEC Institution of Technology, pp. M2D.1-M2D.9.

Corter, J. E., Nickerson, J. V., Esche, S. K., \& Chassapis, C. (2004). Remote versus hands-on labs: A comparative study. Proceedings of the 34th ASEE/IEEE Frontiers in Education Conference, Savannah, GA.

Ginsberg, S. (2007, January 15). Rio Rancho office space graduating to class A ranks. New Mexico Business Weekly.

Hardaway, D., Hogan, M. J., \& Mathieu, R. G. (2005). Outsourcing the university computer lab. IEEE Computer, 38(9), 100-102.

Hawkins, B. L., \& Rudy, J. A. (2006). EDUCAUSE core data service: Fiscal Year 2005 summary report. EDUCAUSE. Retrieved from http://net.educause.edu/ir/library/pdf/pub8003.pdf 
Hawkins, B. L., \& Oblinger, D. G. (2007). The myth about the need for public computer labs: 'Students have their own computers, so public labs are no longer needed.' EDUCAUSE Review, 42(1), 10-11.

Ko, C. C., Chen, B. M., Chen, S. H., Ramakrishnan, V., Chen, R., Hu, S. Y., \& Zhuang, Y. (2000). A largescale web-based virtual oscilloscope laboratory experiment. Engineering Science Education Journal, 9(2), 69-76.

Ma, J., \& Nickerson, J. V. (2006). Hands-on, simulated, and remote laboratories: A comparative literature review. ACM Computing Surveys, 38(3), 1-37.

Mann, V. \& Parashar, M. (2002). Engineering an interoperable computational collaboratory on the grid. Concurrency and Computation: Practice and Experience, 14, 1569-1593.

Oberdick, J. (2006). 2006 FACAC student survey reveals trends in student technology use of interest to faculty. Retrieved May 29, 2007 from http://css.psu.edu/news/nlsp07/faccac.html

Ogot, M., Elliott, G., \& Glumac, N. (2003). An assessment of in-person and remotely operated laboratories. Journal of Engineering Education, 92(1), 57-62.

Ross, R. J., Boroni, C. M., Goosey, F. W., Grinder, M., \& Wissenbach, P. (1997). Weblab! A universal and interactive teaching, learning, and laboratory environment for the world wide web. Proceedings of the 28th SIGCSE Technical Symposium on Computer Science Education, San Jose, CA, pp. 199-203.

Sicker, D. C., Lookabaugh, T., Santos, J., \& Barnes, F. (2005). Assessing the effectiveness of remote networking laboratories. Proceedings of the 35th ASEE/IEEE Frontiers in Education Conference, Boulder, CO, pp. 7-12.

Winer, L. R., Chomienne, M., \& Vazquez-Abad, J. (2000). A distributed collaborative science learning laboratory on the Internet. American Journal of Distance Education, 14(1).

Zimmerli, S., Steinemann, M. A., \& Braun, T. (2003). Resource management portal for laboratories using real devices on the Internet. ACM SIGCOMM Comput. Commun. Review, 53(3), 145-151.

\section{Appendix}

In order to examine some of the statistical properties of the questionnaire, we converted the data into a form usable by SPSS. The coding is summarized in Table 5 below.

Table 5. Questionnaire coding for SPSS analysis

\begin{tabular}{|c|c|c|}
\hline Question & Variable Name & Coding \\
\hline 1. Hours using PLAB & PLAB Use & Ordinal, None $=1$, more than 10 hours $=4$ \\
\hline 2. Hours using VLAB & VLAB Use & Ordinal, None $=1$, more than 10 hours $=4$ \\
\hline 3. Applications used & Used & $\begin{array}{l}\text { Binary coded variables for each software } \\
\text { package, plus one for "none" }(1=\text { has used this } \\
\text { software on the VLAB })\end{array}$ \\
\hline $\begin{array}{l}\text { 4. VLAB easier/harder to use than } \\
\text { PLAB }\end{array}$ & VLAB EOU & $\begin{array}{l}\text { Much More Difficult }=1 \text {, Much Less Difficult } \\
=5\end{array}$ \\
\hline $\begin{array}{l}\text { 5. VLAB more/less convenient } \\
\text { than PLAB }\end{array}$ & VLAB Convenience & $\begin{array}{l}\text { Much Less Convenient }=1 \text {, Much More } \\
\text { Convenient }=5\end{array}$ \\
\hline 6. Is VLAB valuable & VLAB Valuable & binary yes $=1$ \\
\hline 7. Is VLAB Accessibile & VLAB Accessibility & Rarely or Never $=1$, Almost Always $=4$ \\
\hline 8. Access locations & AccessPlace & $\begin{array}{l}\text { Binary coded variables for each location, plus } \\
\text { one for "none" ( } 1=\text { has used VLAB in that } \\
\text { location) }\end{array}$ \\
\hline
\end{tabular}




\begin{tabular}{|l|l|l|}
\hline \multicolumn{1}{|c|}{ Question } & \multicolumn{1}{|c|}{ Variable Name } & \multicolumn{1}{c|}{ Coding } \\
\hline 9. Devices used to access VLAB & AccessDev & $\begin{array}{l}\text { Binary coded variables for each device, plus } \\
\text { one for "none" (1 = has used VLAB with that } \\
\text { device) }\end{array}$ \\
\hline 10. When VLAB is accessed & AccessTime & $\begin{array}{l}\text { Binary coded variables for each time, plus one } \\
\text { for "none" (1 = has used VLAB at that time) }\end{array}$ \\
\hline $\begin{array}{l}\text { 11. PLAB preferable for some } \\
\text { tasks? }\end{array}$ & Prefer PLAB to VLAB & Binary, yes=1 \\
\hline $\begin{array}{l}\text { 12. VLAB preferable for some } \\
\text { tasks? }\end{array}$ & Prefer VLAB to PLAB & Binary, yes=1 \\
\hline 13. Reasons for 11/12 & Not coded & Not coded \\
\hline 14. Age & Age & as entered \\
\hline 15. Gender & Gender & Binary, Male=0 \\
\hline 16. Degree & Degree & $\begin{array}{l}\text { Binary coded variables for each degree }(1= \\
\text { pursuing that degree) }\end{array}$ \\
\hline 17. Concentration & Conc & $\begin{array}{l}\text { Binary coded variables for each concentration } \\
\text { mentioned by anyone, plus "none" }(1= \\
\text { respondent has that concentration) }\end{array}$ \\
\hline 18. Own a laptop & Own Laptop & Binary, owns a laptop =1 \\
\hline 19. Laptop checkout frequency & Laptop Checkout Freq & Rarely or Never =1, Frequently = 4 \\
\hline $\begin{array}{l}\text { 20. Type of PC used most } \\
\text { frequently }\end{array}$ & Owns Mac, Owns PC & $\begin{array}{l}\text { Binary coded variables, 1 = respondent uses } \\
\text { that type of computer }\end{array}$ \\
\hline 21. Computer ability & Class & novice = 1, power user =4 \\
\hline Source of survey response & $\begin{array}{l}\text { Binary coded variables for class in which } \\
\text { survey was taken; } 1=\text { respondent was in that } \\
\text { class }\end{array}$ \\
\hline
\end{tabular}

Having coded all the questions, we then ran bivariate correlations on all of them using SPSS version 15.0.1, calculating the Pearson correlation coefficient for each correlation, and then we looked for correlations that were significantly different from 0 (using an $\alpha$ of .05 using a twotailed test). Note that because many correlations were examined, these significance levels are not correct and should be Bonferroni corrected. However, since we are in an exploratory phase and not attempting to use the results quantitatively, we use these correlations as suggestions needing future confirmation. Use of these levels is not inappropriate for the qualitative examination we are primarily performing.

Many of the revealed correlations were fairly obvious, such as respondents seeking MBAs were older, MIS concentrations were more common in the surveys taken in the Information Systems classes, and daytime use corresponded more to use from work or school, while nighttime use tended to be from home. Other correlations were, however, more interesting. These are summarized in Table 6. 
Table 6. Interesting correlations

\begin{tabular}{|c|c|c|c|}
\hline $\begin{array}{l}\text { Groups for } \\
\text { Discussion }\end{array}$ & \multicolumn{2}{|c|}{ Correlates } & $\begin{array}{c}\text { Correlation (p } \\
\text { value) }\end{array}$ \\
\hline \multirow[t]{11}{*}{ A } & Class 636/639 & AccessTime Eve & $.262(.015)$ \\
\hline & Class 636/639 & AccessTime Weekday & $.442(<.001)$ \\
\hline & Class 636/639 & AccessTime Weekend & $.492(<.001)$ \\
\hline & Conc IA & AccessPlace Travel & $.307(.004)$ \\
\hline & Conc MIS & AccessPlace Home & $.236(.029)$ \\
\hline & Conc MIS & AccessPlace Travel & $.488(<.001)$ \\
\hline & Conc MIS & AccessTime Night & $.507(<.001)$ \\
\hline & Conc Mktg & AccessTime Eve & $-.300(.005)$ \\
\hline & Conc Mktg & AccessTime Night & $-.261(.015)$ \\
\hline & Conc Mktg & AccessTime Weekday & $-.305(.004)$ \\
\hline & Conc Mktg & AccessTime Weekend & $-.453(<.001)$ \\
\hline \multirow[t]{2}{*}{ B } & Laptop Checkout Freq & AccessTime Weekday & $-.218(.048)$ \\
\hline & Laptop Checkout Freq & AccessTime Weekend & $-.220(.046)$ \\
\hline $\mathrm{D}$ & Prefer PLAB to VLAB & Conc IA & $.260(.016)$ \\
\hline $\mathrm{F}$ & Prefer VLAB to PLAB & AccessTime Night & $.244(.024)$ \\
\hline \multirow[t]{3}{*}{$\mathrm{C}$} & Prefer VLAB to PLAB & Conc IA & $.289(.007)$ \\
\hline & Prefer VLAB to PLAB & Conc MIS & $.221(.040)$ \\
\hline & Prefer VLAB to PLAB & Conc Mktg & $-.214(.048)$ \\
\hline $\mathrm{D}$ & Prefer VLAB to PLAB & Prefer PLAB to VLAB & $.474(<.001)$ \\
\hline \multirow[t]{3}{*}{$\mathrm{E}$} & VLAB Accessibility & AccessPlace Home & $.243(.024)$ \\
\hline & VLAB Accessibility & AccessTime Eve & $.216(.046)$ \\
\hline & VLAB Accessibility & AccessTime Weekend & $.291(.007)$ \\
\hline \multirow[t]{2}{*}{$\mathrm{F}$} & VLAB Accessibility & Degree BBA & $-.327(.003)$ \\
\hline & VLAB Accessibility & Degree MBA & $.277(.011)$ \\
\hline G & VLAB Convenience & AccessDev Tablet & $-.320(.003)$ \\
\hline \multirow[t]{5}{*}{$\mathrm{E}$} & VLAB Convenience & AccessPlace Home & $.233(.031)$ \\
\hline & VLAB Convenience & AccessPlace Work & $.226(.036)$ \\
\hline & VLAB Convenience & AccessTime Eve & $.231(.032)$ \\
\hline & VLAB Convenience & AccessTime Night & $.212(.025)$ \\
\hline & VLAB Convenience & AccessTime Weekday & $.242(.025)$ \\
\hline $\mathrm{F}$ & VLAB Convenience & Degree BBA & $-.221(.044)$ \\
\hline $\mathrm{F}$ & VLAB Convenience & Degree MBA & $.220(.046)$ \\
\hline
\end{tabular}




\begin{tabular}{|c|c|c|c|}
\hline Groups for & \multicolumn{2}{|c|}{ Correlates } & Correlation (p \\
\hline \multirow[t]{4}{*}{ B } & VLAB Convenience & Laptop Checkout Freq & $-.244(.026)$ \\
\hline & VLAB Convenience & PLAB Use & $-.285(.008)$ \\
\hline & VLAB Convenience & Prefer PLAB to VLAB & $-.297(.005)$ \\
\hline & VLAB EOU & Prefer PLAB to VLAB & $-.275(.011)$ \\
\hline \multirow[t]{10}{*}{$\mathrm{H}$} & VLAB Use & AccessPlace Travel & $.278(.009)$ \\
\hline & VLAB Use & Access Time Eve & $.245(.023)$ \\
\hline & VLAB Use & AccessTime Night & $.389(<.001)$ \\
\hline & VLAB Use & AccessTime Weekend & $.436(<.001)$ \\
\hline & VLAB Use & Class $636 / 639$ & $.537(<.001)$ \\
\hline & VLAB Use & Conc IA & $.219(.035)$ \\
\hline & VLAB Use & Conc MIS & $.391(<.001)$ \\
\hline & VLAB Use & Conc Mktg & $-.493(<.001)$ \\
\hline & VLAB Use & Degree BBA & $-.417(<.001)$ \\
\hline & VLAB Use & Degree MBA & $.346(.001)$ \\
\hline \multirow[t]{2}{*}{ B } & VLAB Use & PLAB Use & $.299(.004)$ \\
\hline & VLAB Valuable & Laptop Checkout Freq & $-.248(.024)$ \\
\hline \multirow[t]{3}{*}{ I } & VLAB Valuable & VLAB Accessibility & $.215(.047)$ \\
\hline & VLAB Valuable & VLAB Convenience & $.506(<.001)$ \\
\hline & VLAB Valuable & VLAB EOU & $.220(.045)$ \\
\hline
\end{tabular}

Grouping A designates correlations associated with type of use/users and access time. The students in 636/639 tended to be more technically proficient, were doing more technically challenging tasks, and were remote students. This fits with their use of the VLAB more intensively and from more locations than the 481 students.

Grouping B shows that the VLAB did have some effect on the use of checked-out laptops. Students who were more likely to use the VLAB or considered it valuable were less likely to check out laptops. Similarly, students who found the VLAB to be more convenient were likelier to use the PLAB less. Additionally, students who considered the VLAB to be more convenient or easy to use were less likely to have tasks for which they preferred the PLAB. This supports the idea that the VLAB can reduce requirements for physical resources. On the other hand, VLAB use did increase with increased PLAB use, so students that were more likely to use the VLAB were more likely to use computing resources in general.

Grouping $\mathrm{C}$ indicates that more technically proficient students were likelier to prefer the VLAB over the PLAB for at least some tasks and that less technically inclined students were less likely to prefer the VLAB. This points to the possibility for some gains in student acceptance of the VLAB by providing better education on its use.

Grouping D simply shows us that users that have any preference for the VLAB or the PLAB for certain tasks have a tendency to have preferences for different tasks that take into account the nature of the lab; thus they have a preference for the PLAB on some tasks and the VLAB on others. 
Grouping E underscores the expectation that students who access the VLAB from more places will consider the VLAB to be more accessible and convenient.

Grouping F shows that students working on a BBA view the lab as less accessible and less convenient than MBA students. On reflection, what this likely represents is that MBA students are likelier to see the PLAB as not as convenient as the BBA students, since the MBA students are likelier to live off campus. Thus, the convenience and the accessibility of the VLAB is a more important quality to them than it is to the BBA students.

Grouping $\mathrm{G}$ is interesting in that it underscores the resource intensive nature of the VLAB. Students using tablet PCs were likelier to see the VLAB as less accessible, likely due to the nature of the tablet PC.

Grouping $\mathrm{H}$ underscores the idea that the VLAB allows students to work remotely. Many of those using the VLAB more were using it during hours that the PLAB was not accessible, or at times when they could not go to the PLAB, such as while traveling.

Finally, grouping I shows that there is a strong link between perceptions of the VLAB convenience and accessibility and the perception that the VLAB is a valuable addition to the school's computing resources. Convenience seems to be a stronger driver than accessibility. Ease of use also factors in to this, suggesting that increasing the ease of use of the system, perhaps through some short classes, will improve the value perception even more.

\section{Biographies}

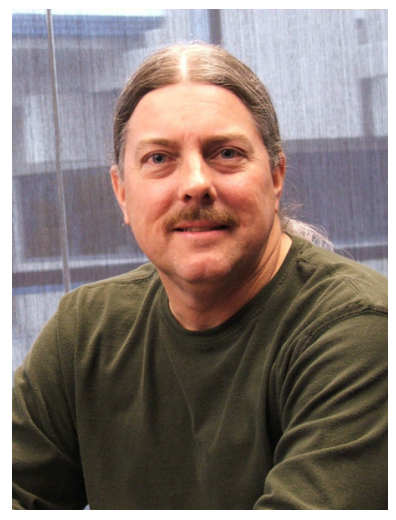

Stephen D. Burd is an Associate Professor of Management. He earned his Ph.D. from Purdue University in 1984 and is a Certified Public Accountant. He has authored textbooks in systems analysis \& design and systems architecture. He has presented and published papers in artificial intelligence, decision support, healthcare costeffectiveness, information assurance, and web-based learning. His current teaching interests include accounting information systems, database management, system architecture, and system/network administration. He serves as co-director of the UNM Center for Information Assurance Research and Education and as Secretary and Treasurer of the New Mexico Telehealth Alliance.

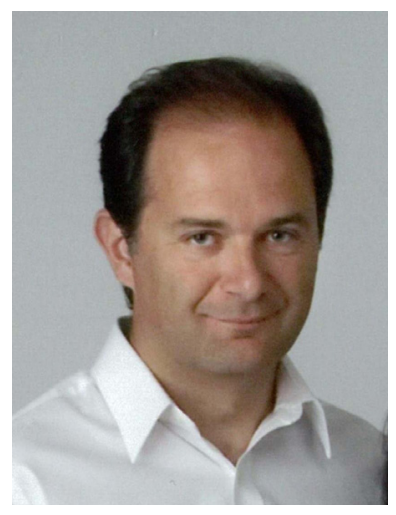

Alessandro F. Seazzu is a Lecturer in Management. He also serves as the Anderson School of Management Information Systems Director and as the Director of the UNM Center for Information Assurance Research and Education. He holds a BBA and MBA from the University of New Mexico. He has presented and published papers in the areas of computer and network security, information assurance, internal auditing, and virtualization. His current teaching interests include introductory and advanced topics in computer security and information assurance. 


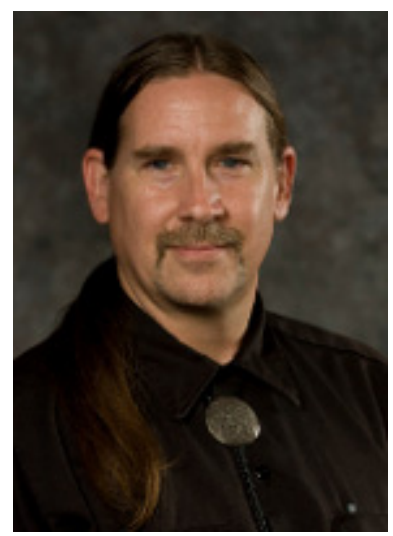

Christopher M. Conway is currently a doctoral student in Information Systems at the University of Arkansas in Fayetteville. He has completed work on an MBA in MIS and Policy and Planning, and is finishing thesis work on an MS in Computer Science from the University of New Mexico. He holds a BA in Computer Science, Mathematical Science, and French from Rice University. He has returned to academia after a 20 year career as a programmer and systems and network administrator. 